\title{
Effect of Lactic Acid Content into on during Miconazole Eye Drops to be Used for Infection Preventive
}

\author{
Kana Yoshimura ${ }^{1}$, Yutaka Inoue ${ }^{1, *}$, Akihiko Koizumi ${ }^{1}$, Mitsuaki Suzuki ${ }^{2}$, Shoko Itakura ${ }^{1}$, Hiroaki Todo ${ }^{1}$, Isamu Murata ${ }^{1}$, and Ikuo \\ Kanamoto $^{1}$
}

${ }^{1}$ Faculty of Pharmacy and Pharmaceutical Sciences, Josai University, Saitama, Japan

${ }^{2}$ Faculty of Science, Josai University, Saitama, Japan

*Corresponding author: Yutaka Inoue, Faculty of Pharmacy and Pharmaceutical Sciences, Josai University, 1-1 Keyakidai, Sakado, Saitama, 3500295, Japan, Tel: +81-49-271-7980; Fax: +81-49-271-7980; E-mail: yinoue@josai.ac.jp

Received: 27 Apr, 2021 | Accepted: 14 May, 2021 | Published: 21 May, 2021

Citation: Yoshimura K, Inoue Y, Koizumi A, Suzuki M, Itakura S, et al. (2021) Effect of Lactic Acid Content into on during Miconazole Eye Drops to be Used for Infection Preventive. J Drug Res Dev 7(1): dx.doi.org/10.16966/2470-1009.160

Copyright: (c) 2021 Yoshimura K, et al. This is an open-access article distributed under the terms of the Creative Commons Attribution License, which permits unrestricted use, distribution, and reproduction in any medium, provided the original author and source are credited.

\begin{abstract}
Purpose: The aims of this study were to prepare a $0.1 \%$ Miconazole (MCZ) eye-drop solution and to evaluate the stability and physical properties of the preparation.

Methods: For $0.1 \%$ MCZ eye-drops (containing $1 \mathrm{mg} / \mathrm{mL} \mathrm{MCZ),} \mathrm{a} \mathrm{Normal} \mathrm{Saline} \mathrm{Solution} \mathrm{(NSS)-added} \mathrm{system} \mathrm{in} \mathrm{which} \mathrm{MCZ} \mathrm{injection} \mathrm{was} \mathrm{diluted} \mathrm{with}$ NSS, an L-lactate Ringer's Solution (LRS)-added system diluted with LRS and NSS, and a lactic acid-added system diluted with lactic acid and NSS were aseptically prepared. The storage conditions for the NSS-added system were dark condition $\left(25^{\circ} \mathrm{C}, \mathrm{RH} 84 \%\right)$, cold condition $\left(4^{\circ} \mathrm{C}\right)$, and severe condition $\left(40^{\circ} \mathrm{C}, \mathrm{RH} 82 \%\right)$. The LRS-added system and the lactic acid-added system were stored only at $4^{\circ} \mathrm{C}$.

Results: MCZ eye-drops diluted with physiological saline showed a reduction in MCZ content to approximately $90 \%$ after 2 weeks of storage at $4^{\circ} \mathrm{C}$, and precipitates were confirmed in the eye-drop solution. The $\mathrm{pH}$ was maintained at 4.8 and the osmolality at $280 \mathrm{mOsmol} / \mathrm{kg}$. When lactic acid was added at concentrations of $1 \%$ and $0.5 \%, \mathrm{MCZ}$ precipitation was confirmed after storage for 4 weeks, and the MCZ content decreased to $\leq 90 \%$, with a $\mathrm{pH}$ of approximately 3.0-3.5. However, when $0.3 \%$ lactic acid was added, the MCZ content was maintained after 4 weeks, but the pH dropped to about 3.9.

Conclusion: These results suggest that storing $\mathrm{MCZ}$ eye-drops at $4^{\circ} \mathrm{C}$ for 7 days is reasonable. In addition, the storage period could be extended up to 4 weeks under conditions of $25^{\circ} \mathrm{C}, \mathrm{RH} 84 \%$ or $40^{\circ} \mathrm{C}, \mathrm{RH} 82 \%$. MCZ eye-drop solution containing $0.3 \%$ lactic acid can remain stable for 2 weeks when stored at $4^{\circ} \mathrm{C}$.
\end{abstract}

Keywords: Miconazole; Eye-drop; Stability; Physical property; Lactic acid; Precipitates

\section{Introduction}

The immune system performs a biological defense function in humans and protects the body from pathogenic microorganisms such as viruses and bacteria. A weakened immune system increases the likelihood of fungal corneal infection or fungal intraocular (uvea) infection [1-2]. For example, it has been reported that preventing eye infections is important in patients receiving chemotherapy and post cataract surgery endophthalmitis [3-4]. Fungal keratitisis among the most refractory to treatment and can cause corneal blindness [5]. In addition, because fungal spores can cause damage to the cornea, healing takes time even if antifungal drugs are used. Antifungal drugs such as Miconazole (MCZ) and amphotericin B are prescribed in the form of eye-drops to prevent eye infections [6-7]. Among them, MCZ has a relatively small molecular weight and is more permeable than other drugs [8]. However, few antifungal eye drops, including MCZ, are not commercially available and are currently being prepared as in-hospital formulations as needed [9].
An in-hospital formulation of MCZ eye-drops has been prepared using MCZ injection (containing 200mg MCZ per ampoule [20mL]) (Figure 1). MCZ is an azole compound having a 5-membered imidazole ring containing two nitrogen atoms, and act on the fungi membrane system (cell membrane and cell wall) [10]. It is a poorly soluble antifungal drug with solubility in water of less than $1 \mu \mathrm{g} /$ $\mathrm{mL}$ [11]. The injectable preparation contains $60.2 \mathrm{~g}$ polyoxyethylene hydrogenated castor oil and $20 \mathrm{mg}$ lactic acid. The MCZ injectable preparation is prescribed for infectious diseases such as mycosis, pulmonary mycosis, gastrointestinal mycosis, and uromycosis caused by Cryptococcus, Candida, Aspergillus, and Coccidioides. The $\mathrm{pH}$ of the solution is 3.9-4.9, and the osmotic pressure to Normal Saline Solution (NSS) is $0.05-0.20$.

As a self-imposed control, the MCZ eye-drop solution is stored at $4^{\circ} \mathrm{C}$ (in the dark) for 7 days. When used as an infection control agent in patients planned for long-term cancer chemotherapy, the stability of MCZ eye-drops for $\geq 7$ days needs to be ensured to 


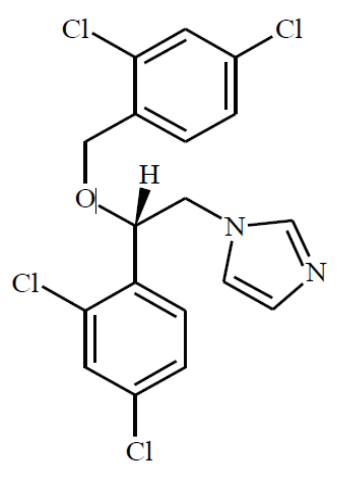

Figure 1: Structure of Miconazole.

expect improvements in patient convenience and in the efficiency of preparation in the pharmacy department. In other words, if it is possible to verify how long the storage period of MCZ eye-drops can be extended, it will not only improve the clinical safety for patients but also reduce the burden of medication guidance for the medical staff [12]. Therefore, the purpose of this study was to prepare $0.1 \%$ $\mathrm{MCZ}$ eye-drops and store the solution at $4^{\circ} \mathrm{C}$ (in the dark), $40^{\circ} \mathrm{C}$ and $82 \%$ relative humidity (RH82\%) (In the dark), and $25^{\circ} \mathrm{C}$ and $\mathrm{RH} 84 \%$ (in the dark). Currently, MCZ eye-drops prepared as in-hospital preparations are stored at $4^{\circ} \mathrm{C}$, so the LRS-added system and lactic acid-added system were stored only at $4^{\circ} \mathrm{C}$. We also aimed to evaluate the stability and physical properties of the preparation. In addition, we report herein the basic challenges to prescribing a new in-hospital formulation of MCZ eye-drops.

\section{Materials and Methods}

\section{Materials}

MCZ injection (MCZ content $200 \mathrm{mg} / 20 \mathrm{~mL}$, lot no. A904) was purchased from Mochida Pharmaceutical Co., Ltd. Isotonic sodium chloride solution (NSS) (lot no. 180903TA) and sodium L-lactate Ringer's Solution (LRS) (lot no. 190418KA) were purchased from Terumo Corporation. L-lactic acid (lot no. L0165) was purchased from Tokyo Chemical Industry Co., Ltd. All other chemicals used were of analytical reagent grade (Fujifilm Wako Pure Chemical Corporation, Tokyo, Japan).

\section{Methods}

Preparation of MCZ eye-drops: For the NSS-added system, MCZ injection was diluted 10 times with NSS to prepare $0.1 \% \mathrm{MCZ}$ eye-drops (containing $1 \mathrm{mg} / \mathrm{mL} \mathrm{MCZ).} \mathrm{The} \mathrm{prepared} \mathrm{eye} \mathrm{drops,} \mathrm{in}$ accordance with the Japanese Pharmacopoeia, $17^{\text {th }}$ Edition (JP XVII), 1) room temperature and dark conditions $\left.\left(25^{\circ} \mathrm{C}, \mathrm{RH} 84 \%\right), 2\right)$ coldtemperature condition $\left(4^{\circ} \mathrm{C}\right)$, and 3$)$ severe $\left(40^{\circ} \mathrm{C}, \mathrm{RH} 82 \%\right)$. Each condition was tested at $\mathrm{N}=10$. In the lactic acid addition system, after adding so that the lactic acid content was $0.3 \%, 0.5 \%$, and $1.0 \%$, it was diluted with NSS to prepare $0.1 \%$ MCZ eye drops. In the LRS addition system, after adding LRS to a lactic acid content of $0.3 \%, 0.5 \%$, and $1.0 \%$, it was diluted with NSS to prepare $0.1 \% \mathrm{MCZ}$ eye drops. The lactic acid- and LRS-added systems were tested only in the $4^{\circ} \mathrm{C}$ condition, and each eye-drop preparation was tested at $\mathrm{N}=3$. This eye drop was prepared on a clean bench by sterile technology based on the JP XVII.

Quantitation of MCZ using high-performance liquid chromatography: The MCZ content of the solutions was quantitated using high-performance liquid chromatography (HPLC; JASCO X-LCTM). Measurement samples containing $900 \mu \mathrm{L}$ acetonitrile, $100 \mu \mathrm{L}$ MCZ eye-drop solutions, and $10 \mathrm{~S} \mu \mathrm{L}$ phosphate were divided into vials and mixed with a vortex mixer. The wavelength of the ultraviolet absorbance detector was set at $224 \mathrm{~nm}$. Separation was performed with an Inertsil ODS-3 column $(4.6 \times 150 \mathrm{~mm}, \phi 5 \mu \mathrm{m})$ at a column temperature of $40^{\circ} \mathrm{C}$. The mobile phase consisted of acetonitrile/distilled water/phosphoric acid (90:10:1), and the flow rate was $0.27 \mathrm{~mL} / \mathrm{min}$. The measurement was performed two times for each sample, and the average value was used for analysis. Based on the calibration curve $(\mathrm{N}=10)$, the LOD and LOQ of a MCZ were determined to be 7.66 and $2.53 \mu \mathrm{g} / \mathrm{mL}(\mathrm{y}=26498 \mathrm{x}+3865.3, \mathrm{R} 2=0.9997)$.

Measurement of $\mathbf{p H}$ : $\mathrm{pH}$ was determined using Horiba $\mathrm{pH}$ meter F-51. $\mathrm{pH}$ was measured at $\mathrm{N}=10$ for the NSS-added system and at $\mathrm{N}=3$ for the lactic acid-added system, and the average values were used for analysis.

Measurement of osmotic pressure: Osmotic pressure measurements were performed using automatic cryoscopic osmometer osmomat $^{\oplus}$ 030-D (Gonotec, Germany). The NSS-added system was tested at $\mathrm{N}=10$ and the lactic acid-added system were tested at $\mathrm{N}=3$, and the average values were obtained. Osmotic pressure was measured two times per sample, and the average value was used for analysis.

Appearance observation: After storage under the different conditions, the solutions were visually inspected.

Molecular weight determination using matrix-assisted laser desorption ionization time-of-flight mass spectrometry: Molecular weight was determined using matrix-assisted laser desorption ionization time-of-flight mass spectrometry (MALDI-TOF MS; JMS-S3000 Spiral $\mathrm{TOF}^{\mathrm{rut}}$ ). Polyethylene glycol 600 was added as a standard reference sample to a concentration of $10 \mathrm{mg} / \mathrm{mL}$, and a standard reference solution was prepared. A-Cyano-4-hydroxy-silicic acid was added to methanol to a concentration of $10 \mathrm{mg} / \mathrm{mL}$ to prepare a matrix solution. To prepare the measurement sample, ethanol was added to a concentration of $10 \mathrm{mg} / \mathrm{mL}$. The standard reference solution/matrix solution was mixed at a 1:10 ratio; the measurement sample solution/matrix solution was mixed at 1:10 and spotted; and the measurement was performed using the internal standard method. The measurement mode was Spiral POS, and the measurement method was SP-2000.spmc. The other conditions were mass range $300-2000 \mathrm{~m} / \mathrm{z}$, laser intensity $22 \%$, and delay time $180 \mathrm{~ns}$.

Statistical processing of data: After performing a one-way ANOVA between each group, each group was compared by Tukey's Test. A risk rate of less than $0.05(\mathrm{p}<0.05)$ was considered statistically significant.

\section{Results}

\section{Saline-added system}

Quantitation of MCZ using HPLC: Table 1 shows the results of MCZ content analysis under storage conditions of $4^{\circ} \mathrm{C}, 40^{\circ} \mathrm{C}$, and $25^{\circ} \mathrm{C}$ (Figure 2). Immediately after preparation, the MCZ content was approximately $1000 \mu \mathrm{g} / \mathrm{mL}$ under all conditions. However, the MCZ content after storage at $4^{\circ} \mathrm{C}$ for 2 weeks decreased to about $890 \mu \mathrm{g} / \mathrm{mL}$. In addition, after 4 weeks of storage, the $\mathrm{MCZ}$ content decreased to approximately $710 \mu \mathrm{g} / \mathrm{mL}$. At $40^{\circ} \mathrm{C}$ and $25^{\circ} \mathrm{C}$, the $\mathrm{MCZ}$ content after 4 weeks of storage was maintained at approximately $1000 \mu \mathrm{g} / \mathrm{mL}$.

Measurement of $\mathbf{p H}$ : Table 1 shows the $\mathrm{pH}$ results of $\mathrm{MCZ}$ eyedrops stored at $4^{\circ} \mathrm{C}, 40^{\circ} \mathrm{C}$ and $25^{\circ} \mathrm{C}$. The $\mathrm{pH}$ immediately after preparation was about 4.9 under all conditions. The $\mathrm{pH}$ of $\mathrm{MCZ}$ ophthalmic solutions stored at $40^{\circ} \mathrm{C}$ and $25^{\circ} \mathrm{C}$ was maintained at 
Table 1: Change in MCZ eye-drops stability at $4^{\circ} \mathrm{C}, 40^{\circ} \mathrm{C}$, and $25^{\circ} \mathrm{C}$.

\begin{tabular}{|c|c|c|c|c|c|c|}
\hline Storage Time (weeks) & Temperature & 0 week & 1 week & 2 week & 3 week & 4 week \\
\hline \multirow{3}{*}{$\mathrm{MCZ}(\mu \mathrm{g} / \mathrm{ml})$} & $4^{\circ} \mathrm{C}$ & $1030.6 \pm 25.5$ & $1030.5 \pm 20.3$ & $892.4 \pm 114.9$ & $788.6 \pm 104.9$ & $708.2 \pm 94.7$ \\
\hline & $40^{\circ} \mathrm{C}$ & $1013.6 \pm 24.1$ & $996.1 \pm 20.6$ & $990.7 \pm 16.5^{*}$ & $1004.2 \pm 43.6^{*}$ & $998.15 \pm 32.4^{*}$ \\
\hline & $25^{\circ} \mathrm{C}$ & $1000.6 \pm 22.7$ & $990.2 \pm 18.1$ & $999.2 \pm 13.9 *$ & $961.9 \pm 16.9 *$ & $977.3 \pm 17.3^{*}$ \\
\hline \multirow{3}{*}{ pH } & $4^{\circ} \mathrm{C}$ & $4.90 \pm 0.01$ & $4.90 \pm 0.01$ & $4.85 \pm 0.03$ & $4.87 \pm 0.04$ & $4.74 \pm 0.08$ \\
\hline & $40^{\circ} \mathrm{C}$ & $4.91 \pm 0.01$ & $4.82 \pm 0.03$ & $4.78 \pm 0.02$ & $4.81 \pm 0.02$ & $4.82 \pm 0.04$ \\
\hline & $25^{\circ} \mathrm{C}$ & $4.89 \pm 0.01$ & $4.87 \pm 0.02$ & $4.89 \pm 0.02$ & $4.92 \pm 0.01$ & $4.91 \pm 0.01$ \\
\hline \multirow{3}{*}{$\begin{array}{l}\text { Osmotic Pressure } \\
\text { (mOmol/kg) }\end{array}$} & $4^{\circ} \mathrm{C}$ & $265.8 \pm 1.7$ & $264.2 \pm 1.3$ & $264.7 \pm 1.9$ & $264.7 \pm 1.9$ & $267.2 \pm 1.7$ \\
\hline & $40^{\circ} \mathrm{C}$ & $264.2 \pm 1.9$ & $267.1 \pm 1.9$ & $274.5 \pm 8.5$ & $272.4 \pm 5.4$ & $276.5 \pm 5.6$ \\
\hline & $25^{\circ} \mathrm{C}$ & $266.7 \pm 1.9$ & $266.0 \pm 1.3$ & $268.5 \pm 1.7$ & $271.7 \pm 1.3$ & $271.7 \pm 0$ \\
\hline \multirow{3}{*}{ Appearance } & $4^{\circ} \mathrm{C}$ & Clear & Clear & Precipitate & Precipitate & Precipitate \\
\hline & $40^{\circ} \mathrm{C}$ & Clear & Clear & Clear & Clear & Clear \\
\hline & $25^{\circ} \mathrm{C}$ & Clear & Clear & Clear & Clear & Clear \\
\hline
\end{tabular}

Values are shown as the mean \pm SD. $\left(n=10\right.$ respectively) ${ }^{*}: p<0.05$ vs $4^{\circ} \mathrm{C}$ (tukey's test).

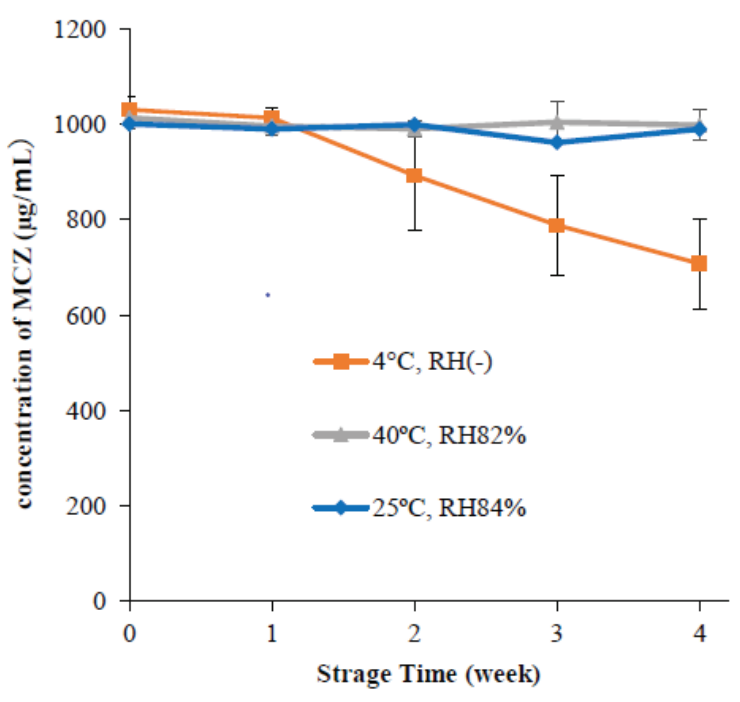

Figure 2: Change in Concentration of $\mathrm{MCZ}$ under storage conditions of $4^{\circ} \mathrm{C}, 40^{\circ} \mathrm{C}$, and $25^{\circ} \mathrm{C}$ at Saline-added system.

approximately $\mathrm{pH} 4.8-4.9$ after 4 weeks of storage. However, at $4^{\circ} \mathrm{C}$, the $\mathrm{pH}$ dropped to about 4.7 after 4 weeks of storage.

Measurement of osmotic pressure: Table 1 shows the osmotic pressure results of $\mathrm{MCZ}$ eye-drops stored at $4^{\circ} \mathrm{C}, 40^{\circ} \mathrm{C}$ and $25^{\circ} \mathrm{C}$. Immediately after preparation, the eye-drop solution with a lactic acid content of $1.0 \%$ had an osmotic pressure of $254 \mathrm{mOsmol} / \mathrm{kg}, 0.5 \%$ had an osmotic pressure of $265 \mathrm{mOsmol} / \mathrm{kg}, 0.3 \%$ had an osmotic pressure of $264 \mathrm{mOsmol} / \mathrm{kg}$. The osmotic pressure of the eye-drops immediately after preparation was about $266 \mathrm{mOsmol} / \mathrm{kg}$ at $4^{\circ} \mathrm{C}$ and $25^{\circ} \mathrm{C}$ and about $264 \mathrm{mOsmol} / \mathrm{kg}$ at $40^{\circ} \mathrm{C}$. However, after storage for 4 weeks, it slightly increased to about $267 \mathrm{mOmol} / \mathrm{kg}$ at $4^{\circ} \mathrm{C}$, about $276 \mathrm{mOmol} / \mathrm{kg}$ at $40^{\circ} \mathrm{C}$, and about $272 \mathrm{mOmol} / \mathrm{kg}$ at $25^{\circ} \mathrm{C}$.

Appearance observation: With respect to appearance, the eyedrop solution was clear immediately after preparation and up to 1 week after storage in all conditions (Table 1). However, at the $4^{\circ} \mathrm{C}$ condition, white precipitates (floats) were observed on the sides or bottom surface of the container after 2 weeks of storage (Figure 3 ). In

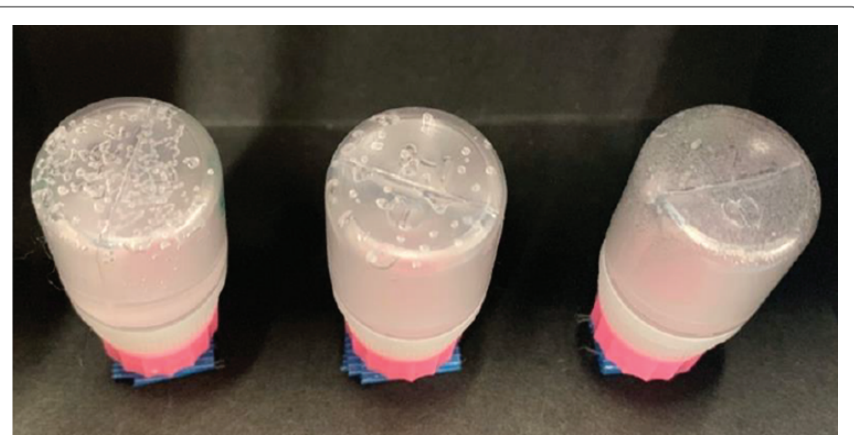

Figure 3: Visual observation of MCZ eye-drop container at Saline-added system (under storage at $4^{\circ} \mathrm{C}$ ) each sample was under storage at $4^{\circ} \mathrm{C}$.

addition, precipitates were confirmed in almost all containers after 3 weeks of storage. At the $40^{\circ} \mathrm{C}$ and $25^{\circ} \mathrm{C}$ conditions, the solutions were clear from immediately after preparation to up to 4 weeks of storage.

Molecular weight measurement using MALDI-TOF MS: In the $4^{\circ} \mathrm{C}$ condition, the appearance of white precipitates was confirmed in the eye-drop solution. Therefore, to verify that the white precipitates were MCZ, molecular weight measurement of the precipitates was performed using MALDI-TOF MS (Figure 4). As a result, peaks were confirmed at $414.9994,416.9967$, and $418.9935 \mathrm{~g} / \mathrm{mol}$, indicating that the white precipitates were MCZ.

MCZ eye-drops prepared by NSS were found to be stable for 4 weeks when stored at $25^{\circ} \mathrm{C}$. However, the presence of a white precipitate was observed at $4^{\circ} \mathrm{C}$ and confirmed to be $\mathrm{MCZ}$ by MALDI-TOFMS measurement. MCZ injection consists of MCZ (200mg), polyoxyethylene hydrogenated castor oil 60 (2g), and lactic acid $(20 \mathrm{mg} / 20 \mathrm{~mL})$. In other words, since the MCZ injection is diluted with NSS, the concentration of lactic acid in the MCZ eyedrops is decreased. In general, chemical degradation is one of the most common changes in the formulation of liquids. This is due to changes in $\mathrm{pH}$, ionic strength, and dielectric constant of the solution in the direction of destabilizing the drug due to coexistence with other ingredients (compounding agents) such as pharmaceutical additives. Next, appearance changes include discoloration and precipitation. Among these, precipitation is caused by the decrease in solubility of the drug substance and the combination drug due to the coexistence 


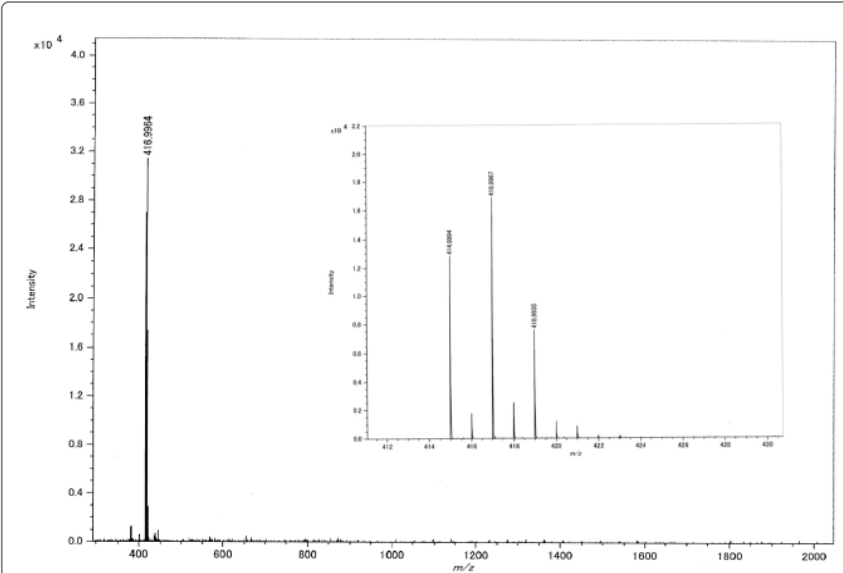

Figure 4: MALDI-TOF MS for molecular weight measurement of precipitate in eye-drop solution.

of the drug substance and the combination drug. In addition, changes in $\mathrm{pH}$ caused by the compounding agent are undesirable because they may lead to irritation during drug administration, even if they are not accompanied by chemical degradation of the drug or discoloration. Therefore, it was considered that the decrease in MCZ content in ophthalmic solution may be due to the change in $\mathrm{pH}$ of the solution due to dilution with physiological saline. LRS dilution system and lactic acid dilution system was prepared and evaluated for stability, assuming that the elution balance would be disrupted due to the decrease in lactic acid concentration in MCZ eye drops /NSS.

\section{LRS-added system}

Quantitation of MCZ using HPLC: Table 2 show the results of the quantitative analysis of MCZ content in eye-drop samples with lactic acid contents of $1 \%, 0.5 \%$, and $0.3 \%$ (Figure 5). Immediately after preparation, the MCZ content was approximately $1000 \mu \mathrm{g} / \mathrm{mL}$ under all conditions. MCZ content was maintained at approximately $1000 \mu \mathrm{g} /$ $\mathrm{mL}$ until 1 week of storage under all conditions. However, the MCZ content after 2 weeks of storage decreased by about $730 \mu \mathrm{g} / \mathrm{mL}$ at $1 \%$, about $830 \mu \mathrm{g} / \mathrm{mL}$ at $0.5 \%$, and about $840 \mu \mathrm{g} / \mathrm{mL}$ at $0.3 \%$. In addition, the MCZ content after 4 weeks of storage was reduced to about $500 \mu \mathrm{g} / \mathrm{mL}$ at $1 \%$, about $540 \mu \mathrm{g} / \mathrm{mL}$ at $0.5 \%$, and about $580 \mu \mathrm{g} / \mathrm{mL}$ at $0.3 \%$.

Measurement of $\mathbf{p H}$ : Table 2 show the results of $\mathrm{pH}$ measurement of eye-drop samples with lactic acid contents of $1 \%, 0.5 \%$, and $0.3 \%$. Immediately after preparation, the eye-drop solution with a lactic acid content of $1.0 \%$ had a $\mathrm{pH}$ of approximately5.4, $0.5 \%$ had a $\mathrm{pH}$ of approximately $4.9,0.3 \%$ the $\mathrm{pH}$ was approximately 5.2 . However, after storage for 4 weeks, the $\mathrm{pH}$ decreased to about 4.9 at $1.0 \%$, about 4.8 at $0.5 \%$, and about 4.7 at $0.3 \%$.

Measurement of osmotic pressure: Table 2 show the results of the osmotic pressure measurements of the eye-drop samples with lactic acid contents of $1 \%, 0.5 \%$, and $0.3 \%$. Immediately after preparation, the eye-drop solution with a lactic acid content of $1.0 \%$ had an osmotic pressure of $254 \mathrm{mOsmol} / \mathrm{kg}, 0.5 \%$ had an osmotic pressure of $265 \mathrm{mOsmol} / \mathrm{kg}, 0.3 \%$ had an osmotic pressure of $264 \mathrm{mOsmol} /$ $\mathrm{kg}$. However, after 4 weeks of storage, the osmotic pressure slightly increased to $267 \mathrm{mOsmol} / \mathrm{kg}$ at $1.0 \%$ and $0.5 \%$, decreased to approximately $258 \mathrm{mOsmol} / \mathrm{kg}$ at $0.3 \%$.

Appearance observation: In the appearance observation, the solution immediately after preparation and up to 1 week was clear for

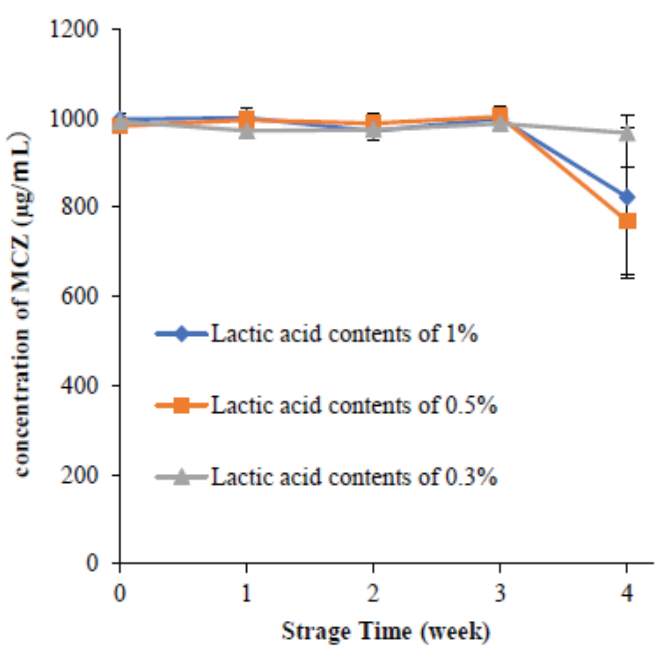

Figure 5: Change in Concentration of $\mathrm{MCZ}$ under storage conditions of $4^{\circ} \mathrm{C}$, at LRS added system (with lactic acid contents of $1 \%, 0.5 \%$, and $0.3 \%$ ).

eye-drop samples with lactic acid contents of $1 \%, 0.5 \%$, and $0.3 \%$ (Table 2). However, white precipitates (floats) were observed on the sides or bottom surface of the containers after 4 weeks of storage (Figure 6).

\section{Lactic acid solution-added system}

Quantitation of MCZ using HPLC: Table 3 shows the results of the quantitative analysis of the eye-drop samples with lactic acid contents of $1 \%, 0.5 \%$, and $0.3 \%$ (Figure 7 ). Immediately after preparation, the MCZ content was approximately $1000 \mu \mathrm{g} / \mathrm{mL}$ under all conditions. MCZ content was maintained at approximately $1000 \mu \mathrm{g} / \mathrm{mL}$ until 3 weeks of storage under all conditions. However, the MCZ content after storage for 4 weeks decreased to about $820 \mu \mathrm{g} / \mathrm{mL}$ at $1 \%$ and about $760 \mu \mathrm{g} / \mathrm{mL}$ at $0.5 \%$. At $0.3 \%$ it was maintained at about $1000 \mu \mathrm{g} / \mathrm{mL}$.

Measurement of $\mathrm{pH}$ : Table 3 show the results of $\mathrm{pH}$ measurements of the eye-drop samples with lactic acid contents of $1 \%, 0.5 \%$, and $0.3 \%$. Immediately after preparation, the eye-drop solution with a lactic acid content of $1.0 \%$ had a $\mathrm{pH}$ of approximately $3.4,0.5 \%$ had a $\mathrm{pH}$ of approximately $3.8,0.3 \%$ the $\mathrm{pH}$ was approximately 4.1 . However, after storage for 4 weeks, the $\mathrm{pH}$ decreased to about 3.1 at $1.0 \%$, about 3.6 at $0.5 \%$, and 3.8 at $0.3 \%$.

Measurement of osmotic pressure: Table 3 show the results of the osmotic pressure measurements of the eye-drop samples with lactic acid contents of $1 \%, 0.5 \%$, and $0.3 \%$. Immediately after preparation, the eye-drop solution with a lactic acid content of $1.0 \%$ had an osmotic pressure of $269 \mathrm{mOsmol} / \mathrm{kg}, 0.5 \%$ had an osmotic pressure of $265 \mathrm{mOsmol} / \mathrm{kg}, 0.3 \%$ had an osmotic pressure of $264 \mathrm{mOsmol} / \mathrm{kg}$. However, after 4 weeks of storage, the osmolality was maintained at $1 \%$ but decreased to $260 \mathrm{mOsmol} / \mathrm{kg}$ at $0.5 \%$ and to about $260 \mathrm{mOsmol} /$ $\mathrm{kg}$ at $0.3 \%$.

Appearance observation: In the appearance observation, the eye-drop solution was clear immediately after preparation and up to 2 weeks of storage under all conditions (Figure 8a). However, the eye-drop samples with lactic acid contents of $1.0 \%$ and $0.5 \%$ were confirmed to have precipitates after 4 weeks of storage. Conversely, the eye-drop solution with $0.3 \%$ lactic acid was clear until 4 weeks of storage (Figure $8 b$ ). 
Table 2: Changes in the stability of MCZ eye-drops at $4^{\circ} \mathrm{C}$ added with $1 \%, 0.5 \%$ and $0.3 \%$ lactate prepared using L-sodium lactate Ringer's solution.

\begin{tabular}{|c|c|c|c|c|c|c|}
\hline Storage Time (weeks) & Percentage & 0 week & 1 week & 2 week & 3 week & 4 week \\
\hline \multirow{3}{*}{$\mathrm{MCZ}(\mu \mathrm{g} / \mathrm{ml})$} & $1 \%$ & $989.5 \pm 18.6$ & $969.8 \pm 18.1$ & $733 \pm 172.9$ & $593 \pm 77.9$ & $509.2 \pm 27$ \\
\hline & $0.50 \%$ & $1030.6 \pm 25.5$ & $1013.5 \pm 20.3$ & $826.1 \pm 142.7$ & $708.2 \pm 94.7$ & $542.9 \pm 44.8$ \\
\hline & $0.30 \%$ & $973.5 \pm 12.3$ & $975.9 \pm 7.8$ & $840.4 \pm 66.8$ & $672.4 \pm 22.2$ & $589.3 \pm 17.5$ \\
\hline \multirow{3}{*}{$\mathrm{pH}$} & $1 \%$ & $5.49 \pm 0.01$ & $5.39 \pm 0.03$ & $5.17 \pm 0.03$ & $5.04 \pm 0.01$ & $4.97 \pm 0.03$ \\
\hline & 0.50 & $4.9 \pm 0.01$ & $4.9 \pm 0.01$ & $4.9 \pm 0.01$ & $4.84 \pm 0.05$ & $4.82 \pm 0.02$ \\
\hline & $0.30 \%$ & $5.28 \pm 0.01$ & $5.25 \pm 0.02$ & $5.05 \pm 0.04$ & $4.8 \pm 0.01$ & $4.73 \pm 0.04$ \\
\hline \multirow{3}{*}{$\begin{array}{l}\text { Osmotic Pressure } \\
\text { (mOmol/kg) }\end{array}$} & $1 \%$ & $253.8 \pm 0.5$ & $254.7 \pm 1.0$ & $264.7 \pm 1.9$ & $267.2 \pm 1.7$ & $267 \pm 0.4$ \\
\hline & 0.50 & $265.8 \pm 1.7$ & $264.2 \pm 1.3$ & $264.7 \pm 1.9$ & $267.2 \pm 1.7$ & $267.5 \pm 1.1$ \\
\hline & $0.30 \%$ & $264.5 \pm 1.0$ & $263.5 \pm 0.8$ & $259.5 \pm 1.0$ & $258.8 \pm 1.0$ & $258 \pm 1.8$ \\
\hline \multirow{3}{*}{ Appearance } & $1 \%$ & Clear & Clear & Precipitate & Precipitate & Precipitate \\
\hline & $0.50 \%$ & Clear & Clear & Precipitate & Precipitate & Precipitate \\
\hline & $0.30 \%$ & Clear & Clear & Precipitate & Precipitate & Precipitate \\
\hline
\end{tabular}

Values are shown as the mean $\pm S D,(n=3$ respectively).

Table 3: Changes in the stability of $\mathrm{MCZ}$ eye-drops at $4^{\circ} \mathrm{C}$ added with $1 \%, 0.5 \%$ and $0.3 \%$ lactic acid prepared.

\begin{tabular}{|c|c|c|c|c|c|c|}
\hline Storage Time (weeks) & Percentage & 0 week & 1 week & 2 week & 3 week & 4 week \\
\hline \multirow{3}{*}{$\mathrm{MCZ}(\mu \mathrm{g} / \mathrm{ml})$} & $1 \%$ & $997.7 \pm 12.3$ & $1000.8 \pm 23.7$ & $971.2 \pm 20.4$ & $999.5 \pm 6.0$ & $823.1 \pm 183.2^{*}$ \\
\hline & $0.50 \%$ & $981.9 \pm 3.7$ & $995.9 \pm 16.1$ & $988.4 \pm 21.1$ & $1003.6 \pm 22.9$ & $769.2 \pm 120.7^{*}$ \\
\hline & $0.30 \%$ & $992.8 \pm 16.8$ & $971.8 \pm 8.1$ & $974.2 \pm 8.9$ & $998 \pm 16.4$ & $967 \pm 12.8$ \\
\hline \multirow{3}{*}{$\mathrm{pH}$} & $1 \%$ & $3.41 \pm 0.01$ & $3.32 \pm 0.07$ & $3.3 \pm 0.03$ & $3.09 \pm 0.02$ & $3.11 \pm 0.01$ \\
\hline & 0.50 & $3.85 \pm 0.02$ & $3.9 \pm 0.06$ & $3.7 \pm 0.01$ & $3.5 \pm 0.02$ & $3.56 \pm 0.02$ \\
\hline & $0.30 \%$ & $4.17 \pm 0.01$ & $4.19 \pm 0.03$ & $4.02 \pm 0.02$ & $3.86 \pm 0.03$ & $3.83 \pm 0.03$ \\
\hline \multirow{3}{*}{$\begin{array}{l}\text { Osmotic Pressure } \\
\text { (mOmol/kg) }\end{array}$} & $1 \%$ & $269.8 \pm 1.8$ & $269.0 \pm 0.5$ & $267.3 \pm 2.9$ & $267.6 \pm 1.5$ & $270 \pm 0.8$ \\
\hline & 0.50 & $265.3 \pm 0.5$ & $264.5 \pm 1.5$ & $261.2 \pm 1.0$ & $259.8 \pm 1.3$ & $260.5 \pm 0.8$ \\
\hline & $0.30 \%$ & $264.2 \pm 0.7$ & $263.3 \pm 0.7$ & $261 \pm 1.3$ & $260.5 \pm 2.6$ & $260 \pm 1.8$ \\
\hline \multirow{3}{*}{ Appearance } & $1 \%$ & Clear & Clear & Clear & Clear & Precipitate \\
\hline & $0.50 \%$ & Clear & Clear & Clear & Clear & Precipitate \\
\hline & $0.30 \%$ & Clear & Clear & Clear & Clear & Clear \\
\hline
\end{tabular}

Values are shown as the mean \pm SD ( $n=3$ respectively), * $p<0.05$ vs $0.3 \%$ (tukey's test).

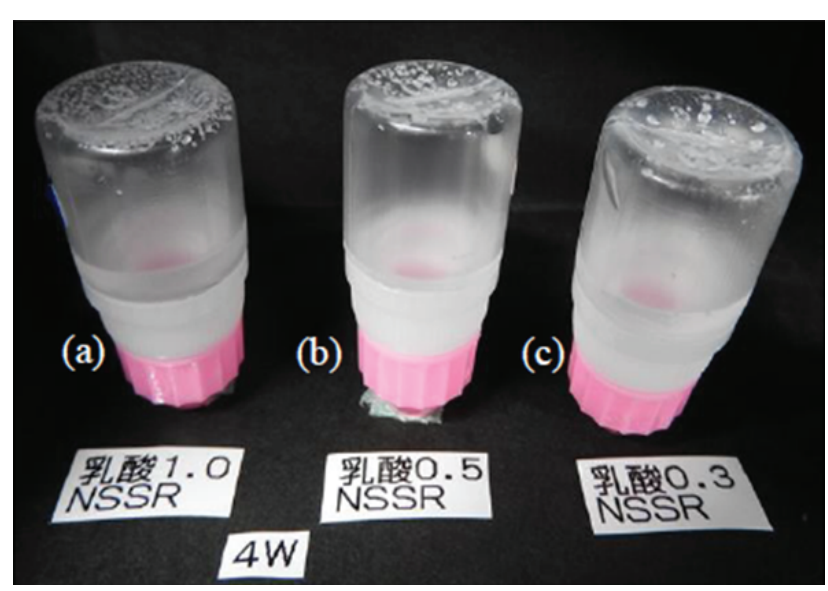

Figure 6: Visual observation of $\mathrm{MCZ}$ eye-drop container (under storage at $4^{\circ} \mathrm{C}, 2$ weeks).

(a) With $1 \%$ lactic acid prepared using L-sodium lactate Ringer's solution.

(b) With $0.5 \%$ lactic acid prepared using L-sodium lactate Ringer's solution.

(c) With $0.3 \%$ lactic acid prepared using L-sodium lactate Ringer's solution.

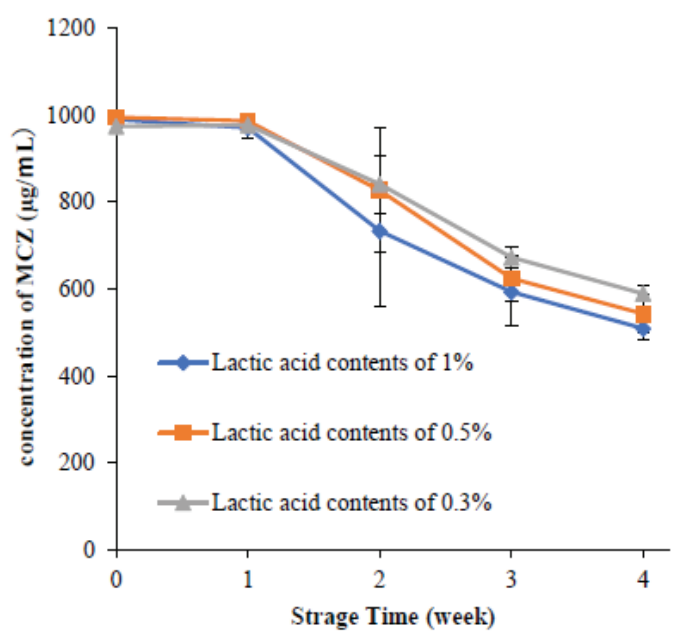

Figure 7: Change in Concentration of $\mathrm{MCZ}$ under storage conditions of $4^{\circ} \mathrm{C}$, at lactic acid added system (with lactic acid contents of $1 \%$, $0.5 \%$, and $0.3 \%)$. 


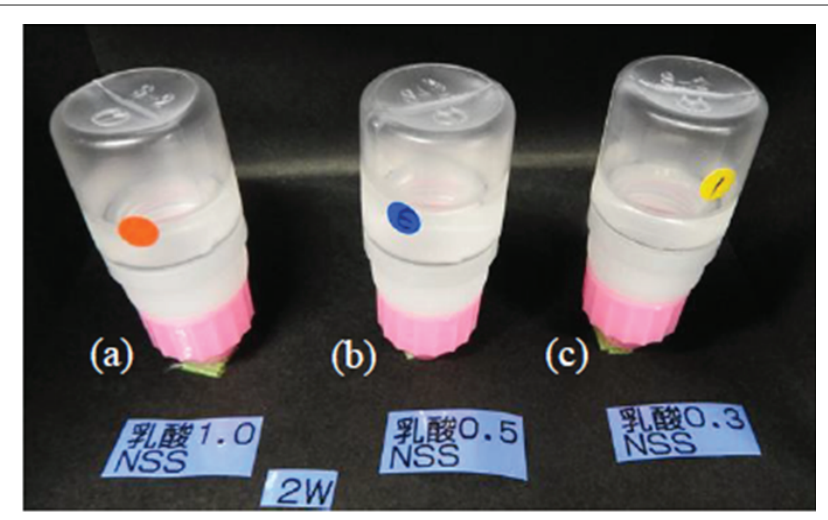

Figure 8a: Visual observation of $\mathrm{MCZ}$ eye-drop container (under storage at $4^{\circ} \mathrm{C}, 2$ weeks).

(a)With $1 \%$ lactic acid prepared using lactic acid reagent.

(b)With $0.5 \%$ lactic acid prepared using lactic acid reagent.

(c)With $0.3 \%$ lactic acid prepared using lactic acid reagent.

\section{Discussion}

In the eye-drop samples diluted with NSS, the MCZ content decreased to approximately $90 \%$ after 2 weeks of storage at $4^{\circ} \mathrm{C}$. Furthermore, white precipitates were confirmed in the solution, which were identified to be MCZ. However, at $40^{\circ} \mathrm{C}$ and $25^{\circ} \mathrm{C}$, the MCZ content was maintained at almost $100 \%$ after 4 weeks. The reason why the $\mathrm{MCZ}$ content was kept at $25^{\circ} \mathrm{C}$ and $40^{\circ} \mathrm{C}$ was thought to be related to the temperature-dependent solubility of MCZ. Furthermore, significant changes in $\mathrm{pH}$ and osmotic pressure were observed under all storage conditions. In general, it is known that the difference in osmotic pressure does not cause much discomfort in ocular tissue at $0.6-2.0 \%$ (0.72 as an osmotic pressure ratio) in terms of sodium chloride [13]. For example, medical glaucoma eye-drops have an osmotic pressure ratio of 0.6 to 1.6 and a $\mathrm{pH}$ in the range of 4 to 8 [14]. Generally, the $\mathrm{pH}$ and osmolality of MCZ eye-drops are suitable after 4 weeks. No precipitation was confirmed at $25^{\circ} \mathrm{C}$ and $40^{\circ} \mathrm{C}$. However, since a precipitate was confirmed at $4^{\circ} \mathrm{C}$, the effect of temperature was also inferred. Therefore, when stored at $4^{\circ} \mathrm{C}$, the $\mathrm{MCZ}$ content remained reasonable after 1 week of storage. Further, the results suggested that room temperature storage $\left(15-25^{\circ} \mathrm{C}\right)$ is possible, which could improve not only the medication compliance but also the convenience of patients. In addition, it could also reduce the burden of medication guidance for the medical staff [15].

MCZ eye-drops were prepared by diluting an MCZ injectable preparation 10 times with NSS. The MCZ injectable preparation is composed of $200 \mathrm{mg} \mathrm{MCZ,} 2 \mathrm{~g}$ polyoxyethylene-cured castor oil 60 , and $20 \mathrm{mg} / 20 \mathrm{~mL}$ lactic acid. Therefore, we hypothesized that diluting the MCZ eye-drops 10 times with saline disrupted the dissolution balance owing to the decrease in lactic acid concentration. Therefore, the stability of the lactic acid and LRS-added systems was evaluated. In the LRS-added system, precipitation was confirmed in 2 weeks in samples with lactic acid contents of $1 \%, 0.5 \%$, and $0.3 \%$. In addition, the MCZ content decreased. LRS contains $\mathrm{Ca}$ and Mg. MCZ nitrate creams are commercially available. MCZ is a basic drug containing an imidazole ring in its structure, with improved solubility under acidic conditions as nitrate (i.e., MCZ is not precipitated), and is considered to have good compatibility as a cream formulation [16]. However, in the LRS-added system, it was speculated that the lactic acid contained in the MCZ injectable preparation and the MCZ interacted and

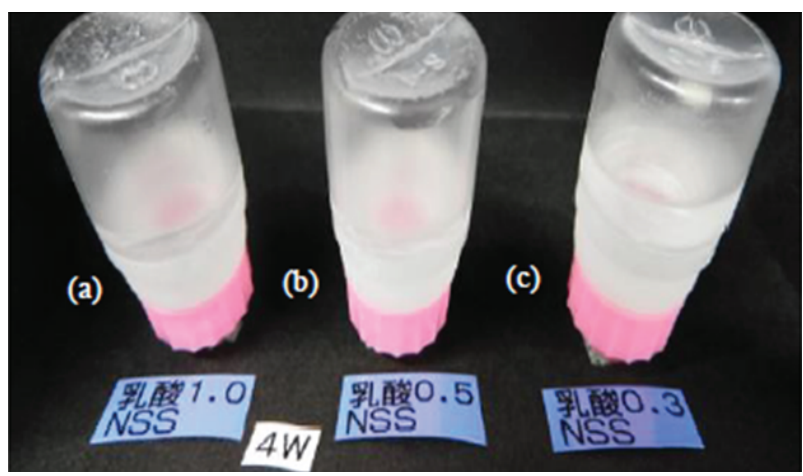

Figure 8b: Visual observation of $\mathrm{MCZ}$ eye-drop container (under storage at $4^{\circ} \mathrm{C}, 4$ weeks).

(a)With $1 \%$ lactic acid prepared using lactic acid reagent.

(b) With $0.5 \%$ lactic acid prepared using lactic acid reagent. (c)With $0.3 \%$ lactic acid prepared using lactic acid reagent.

became dispersed in the aqueous solution as Ca lactate and Mg lactate, which affected the stability of the MCZ eye-drops.

In the lactic acid-added system, precipitates were confirmed at 4 weeks and the MCZ content was also decreased in the samples with $0.5 \%$ and $1 \%$ lactic acid. However, in the case of samples with $0.3 \%$ lactic acid, precipitation was not observed even after 4 weeks. In addition, the MCZ content was maintained at almost $100 \%$. As MCZ is a basic drug, it is present in solutions as ions when the $\mathrm{pH}$ is acidic. However, in eye-drops containing $1 \%$ and $0.5 \%$ lactic acid with a $\mathrm{pH}$ of approximately 3.1-3.5, precipitation was confirmed. The $\mathrm{pH}$ range of the MCZ injection solution ( $\mathrm{pH}$ 3.9-4.9) was a factor in this result. At a lactic acid content of $0.3 \%$, the $\mathrm{pH}$ was almost approximately 3.9 after 4 weeks, which was considered to have contributed to the maintenance of the MCZ content. In addition, even if the polyoxyethylene hydrogenated castor oil contained in the MCZ injectable preparation was diluted with physiological NSS and additional lactic acid was added, good compatibility among MCZ, lactic acid, and castor oil was obtained, as in the MCZ injectable preparation [10]. However, it was inferred that the MCZ content decreased as a result. Not only may the effect of $\mathrm{pH}$ by adding $0.3 \%$ lactic acid to $\mathrm{MCZ}$, but also polyoxyethylene hydrogenated castor oil contributes to the stability. Polyoxyethylene hydrogenated castor oil is also considered to be an additive necessary for the stable dispersion of MCZ in solution. MCZ $0.1 \%$ eye-drops are currently used as an in-hospital formulation to prevent eye infection in patients undergoing cancer chemotherapy. Another fungal drug, voriconazole, has also been prepared as an in-hospital formulation in the form of eye-drops, and its stability has been reported [17]. In this study, MCZ eye drops was found to be stable at $0.3 \%$ lactic acid for 4 weeks from the viewpoint of maintaining the MCZ content. However, the $\mathrm{pH}$ after storage for 3 weeks was less than 4 . Regarding the comfort of use for patients, we are concerned about irritation to the eyes. From the above, 2 weeks is currently considered to be adequate for the stability of the $0.3 \%$ lactic acid system. In the present study, the decrease in the content of MCZ was suppressed in the lactic acid added system. The reason for this may be as follows. In the first place, MCZ is a basic drug. In general, many drugs are weakly acidic or weakly basic compounds. Drug components coexist in solution as a mixture of ionic and nonionic molecules. The $\mathrm{pH}$ of the solution in which the drug is present is determined by the dissociation constant $(\mathrm{pKa})$ of the individual drug, according to the Henderson-Hasselbalch equation 
[18]. In other words, in the case of MCZ, the addition of lactic acid may contribute to its stability by making it an ionic molecule when the liquid nature of the solution is acidic. Moreover, this drug has already been clinically applied. In the future, we believe that it is necessary to accumulate basic research data on in-hospital formulations to confirm their safety and antifungal effects with lactic acid addition through in vitro testing.

MCZ injection already contains $60.2 \mathrm{~g}$ of polyoxyethylene hydrogenated castor oil and $20 \mathrm{mg}$ of lactic acid. In the future, safety tests such as eye irritation will be required in basic research. Also, in this study, the stability of MCZ focused on the diluted solution. In the future, I would like to work on compatibility with eye-drop containers as a research theme.

\section{Conclusion}

At $4^{\circ} \mathrm{C}$ storage, the $\mathrm{MCZ}$ content decreased after 2 weeks and precipitation of MCZ was confirmed in the eye-drop solution. After preparation, eye-drop solutions can be appropriately stored at $4^{\circ} \mathrm{C}$ for 1 week. At $25^{\circ} \mathrm{C}$ storage, the stability of the MCZ eye-drop solution was confirmed even after 4 weeks. The stability of the lactic acid-added system, in which the eye-drop solution was diluted with lactic acid and physiological saline, and that of the LRS-added system were also evaluated. Precipitation of MCZ and a decrease in the MCZ content were confirmed at 2 weeks in samples with $1 \%, 0.5 \%$, and $0.3 \%$ lactic acid from the LRS infusion solution. At 4 weeks, precipitation of MCZ and decreased MCZ content were confirmed in the lactic acid-added system with $1 \%$ and $0.5 \%$ lactic acid. No precipitate was detected in the sample containing $0.3 \%$ lactic acid, and the MCZ content was maintained at almost $100 \%$ even after 4 weeks. However, a decrease in $\mathrm{pH}$ was shown to be irritating to the eyes. Therefore, it is suggested that the addition of $0.3 \%$ lactic acid improves the stability of MCZ eye drops and extends the shelf life from 1 week to 2 weeks.

\section{Author Contributions}

$\mathrm{KY}$ and YI performed the experiments, participated in study design, carried out sampling in prepared the manuscript. AK, MS, HT, and SI participated in experiments. SI carried out sampling and HT planned the study design, analyzed the experimental data and contributed suggestions regarding the manuscript. KY, YI, and IK coordinated the study. KY and YI analyzed Miconazole samples. All authors read and approved the final manuscript.

\section{Acknowledgment}

The authors wish to thank the members of the Pharmacy at Gunma University Hospital for their technical assistance and helpful discussions in the hospital preparation.

\section{Funding}

This research received no external funding.

\section{Conflicts of Interest}

The authors report no conflicts of interest. The authors are solely responsible for the content and writing of the paper.

\section{References}

1. Cheung CSY, Jekielek A, Bakshi N, Muni R, Altomare F, et al. (2018) Clinical features of infectious posterior segment uveitis. Can J Ophthalmol 53: 425-431.
2. Chakravarthy SK, Jayasudha R, Ranjith K, Dutta KRA, Pinna NK, et al. (2018) Alterations in the gut bacterial microbiome in fungal Keratitis patients. PLoS One 13: e0199640.

3. Rothova A, Hajjaj A, Hoog J, Thiadens A, Dalm VA (2019) Uveitis causes according to immune status of patients. Acta Ophthalmol 97: 53-59.

4. Hesam H, Reza M, Mehdi K, Mahmoud J (2016) Post-cataract surgery endophthalmitis: Brief literature review. J Curr Ophthalmol 28: 101105.

5. Rosenblatt MI (2017) Anti-Infective and anti-inflammatory pharmacotherapies. Handb Exp Pharmacol 242: 119-135.

6. Gyanfosu L, Koffuor GA, Kyei S, Danso BA, Donkor KP, et al. (2018) Efficacy and safety of extemporaneously prepared miconazole eyedrops in Candida albicans-induced keratomycosis. Int Ophthalmol 38: 2089-2100.

7. Morand K, Bartoletti AC, Bochot A, Barratt G, Brandely ML, et al. (2017) Liposomal amphotericin B eye-drops to treat fungal keratitis: Physico-chemical and formulation stability. Int J Pharm 344: 150153.

8. Kaur IP, Rana C, Singh H (2008) Development of effective ocular preparations of antifungal agents. ocular pharmacology and therapeutics. J Ocul Pharmacol Ther 24: 481-493.

9. Hospital Pharmacy Europe (2011) Stability of ophthalmic preparations.

10. Heeres J, Meerpoel L, Lewi P (2010) Conazoles. Molecules 15: 41294188.

11. Matsuura K, Kojima H, Haraguchi T, Yoshida M, Suzuki S, et al. (2019) Preparation and characterization of itraconazole- or miconazoleloaded plga microspheres. Chem Pharm Bull 67: 106-111.

12. Pardhi DM, Ramteke VI, Chudhari NG, Parida P, Behera A (2013) Formulation development and compatibility study of Ofloxacin ophthalmic solution in various packaging containers. Elixir Chem Phys Letters 65: 19821-19824.

13. Hiroaki I, Masayuki K, Katsushi M, Teruaki K, Hiroshi F, et al. (1998) Pharmaceutical properties of ophthalmic solutions for rational use total number of drops in one bottle, volume of one drop, Osmotic Ratio and pH. J Hosp Pharm 24: 595-600.

14. Yuichiro $N$ (2015) Analysis of development history of medical glaucoma eye drops. Pharmaceutics 75: 65-71.

15. Akiko O, Katsura I, Hiroyuki T, Eri K, Yasuhiko S, et al. (2010) Formulation design of latanoprost eye-drops to improve the stability at room temperature. J Pharma Sci Technol 70: 324-332.

16. Gautam A, Light B, Purvis T (2017) Stability of two antifungal agents, fluconazole and miconazole, compounded in Humco Recura topical cream to determine beyond-use date. Int J Pharm Compd 21: 154159.

17. Reboredo PA, Fernandez CB, Molina LG, Muner DS, Cabezas CL (2018) Preparation and stability of voriconazole eye-drop solution. Antimicrob Agents Chemother 53: 798-799.

18. Samuel $Y$, Raj P, Doaa AA (2015) Application of the HendersonHasselbalch equation to solubility determination. ADMET \& DMPK 3: 359-362. 